\title{
Recreational cocaine polydrug use impairs cognitive flexibility but not working memory
}

\author{
Lorenza S. Colzato • Mariëtte Huizinga • \\ Bernhard Hommel
}

Received: 22 January 2009/Accepted: 17 August 2009/Published online: 2 September 2009

(C) The Author(s) 2009. This article is published with open access at Springerlink.com

\begin{abstract}
Rationale Chronic use of cocaine is associated with dysfunctions in frontal brain regions and dopamine D2 receptors, with poorer mental flexibility and a reduced ability to inhibit manual and attentional responses. Little is known, however, about cognitive impairments in the upcoming type of recreational cocaine polydrug user (14 g monthly consumption).

Objective We studied whether recreational cocaine polydrug users, who do not meet the criteria for abuse or dependence, showed impairments in working memory (WM) and cognitive flexibility.

Methods Controls and recreational cocaine polydrug users (who abstained from cocaine and other substances more than 1 week) were matched by sex, age, alcohol consumption, and IQ (Raven's Standard Progressive Matrices). Groups were tested by using two cognitive tasks measuring cognitive flexibility and three tasks investigating the maintenance and monitoring of information in WM.

Results Recreational cocaine polydrug users performed significantly worse than controls on tasks tapping cognitive flexibility, but show comparable performance in the active maintenance and monitoring of information in WM.

Conclusions The findings suggest that recreational use of cocaine selectively impairs cognitive flexibility but not the maintenance of information in WM. The inability to adjust
\end{abstract}

L. S. Colzato $(\bowtie) \cdot$ B. Hommel

Institute for Psychological Research \& Leiden Institute for Brain and Cognition, Leiden University,

Postbus 9555,

2300 RB, Leiden, The Netherlands

e-mail: colzato@fsw.leidenuniv.nl

\section{Huizinga}

Department of Psychology, University of Amsterdam,

Amsterdam, The Netherlands behavior rapidly and flexibly may have repercussions for daily life activities.

Keywords Cocaine · Flexibility · WCST · Working memory

\section{Introduction}

Since 2007, cocaine is Europe's second preferred recreational drug after cannabis (European Monitoring Centre for Drugs \& Drug Addiction 2007). Taking cocaine by snorting route is not a "privileged habit" anymore, as it was in the $80 \mathrm{~s}$, but now is affordable for everyone, in particular for recreational purposes. Cocaine has, thus, become a common street drug. At long term, chronic (i.e., daily) use of cocaine is associated with reduced functioning of dopamine D2 (DAD2) receptors (Volkow et al. 1999) and dysfunctions in lateral prefrontal cortex (LPFC), orbitofrontal cortex (OFC; Bolla et al. 1998; Bolla et al. 2004), anterior cingulate, and cerebellum (Hester and Garavan 2004).

Given that all these areas have been shown to play major roles in the control of goal-directed action (Miller 2000), it is not surprising that cocaine dependence is correlated with deficiencies in cognitive control functions (Hester and Garavan 2004; Verdejo-Garcia et al. 2006). Indeed, a majority of studies on chronic cocaine users (see Bolla et al. 1998; Jovanovski et al. 2005, for a review) points in that direction: Chronic users, compared to nonusers, are less able to inhibit overt responses (Fillmore and Rush 2002), perform worse on tasks measuring mental flexibility (Verdejo-Garcia et al. 2006; Verdejo-Garcia and PerezGarcia 2007) and conflict control (Franken et al. 2007), are less able to control visual attention (Kübler et al. 2005), and choose more disadvantageously in a decision-making task (Monterosso et al. 2001). 
So far, however, only few studies have systematically looked into cognitive impairments in the upcoming type of the recreational user, who does not meet the criteria for abuse or dependence but takes cocaine (preferably by snorting route) on a monthly frequency (1 to $4 \mathrm{~g}^{1}$, commonly consumed in only a few sessions). Very recently, Colzato et al. (2008b) found that the spontaneous eyeblink rate, a marker of striatal dopaminergic functioning, is significantly lowered in recreational users, suggesting that even the recreational use of cocaine is associated with a hypoactivity of the subcortical dopamine system. Consistent with this consideration, recreational users exhibit impairments in the inhibition of overt manual responses (Colzato et al. 2007) and of covert attentional responses (Colzato and Hommel 2009), which both are assumed to relying on proper dopaminergic functioning. However, even though the empirical connection between inhibitory control functions and cocaine use is considerable, the causal relation between the two is not straightforward. Indeed, there are some hints to preexisting neurodevelopmental factors that may play a mediating role. For instance, monkeys that have preexisting lowered D2 receptor densities run a higher risks to use cocaine and to become addicted (Nader et al. 2006), and chronic human users may suffer preexisting problems in inhibitory control (Bechara 2005) and impulsivity (Verdejo-Garcia et al. 2008).

Previous studies on recreational use of cocaine have focused on inhibitory control. The ability to inhibit unwanted thoughts and actions is commonly considered an important part of executive control, but it represents just one of a larger set of control functions. In an attempt to categorize the available concepts and measures in a coherent fashion, Miyake and colleagues have investigated the psychometric relationships between the tests and tasks that are commonly used to assess cognitive control (Friedman and Miyake 2004; Friedman et al. 2006; Miyake et al. 2000). Their findings suggest the existence of three major, separable control functions: the "inhibition" of unwanted responses, the "shifting" between tasks and

\footnotetext{
${ }^{1}$ There is no objective way to draw a line between cocaine addicts and recreational users in terms of consumption, but in our past work, a monthly use of $1-4 \mathrm{~g}$ has shown to be an amount that is very typical for users who seem to function normally in everyday life (e.g., as University students) and who in no way meet standard criteria for addiction. Note that according to the statistical bulletin of European Monitoring Center for Drugs and Drug Addiction (2008), the average purity (percentage) of cocaine in The Netherlands, where our data were collected, is rather high $(52.8 \%)$ as compared to other European countries, such as United Kingdom (34.4\%), Denmark (22\%), or Germany $(24.6 \%)$. These differences would need to be taken into account if comparing studies across countries.
}

mental sets (also called "flexibility"), and the "updating" (and monitoring of) working memory (WM) representations. Given that the link between cocaine use and the inhibition function seems to be well established, we in the current study focused on the two remaining functions, flexibility and updating. Previous studies on chronic cocaine users have provided evidence that, apart from inhibitory control, cognitive flexibility is impaired in users (Verdejo-Garcia et al. 2006; Verdejo-Garcia and PerezGarcia 2007), so that we expected that recreational users would also show impairments in tasks tapping flexibility. At the same time, reports concerning performance of cocaine users on tasks tapping WM have been inconsistent. In some cases, cocaine abuse has been shown to negatively affect visual memory (Hoff et al. 1996; O'Malley and Gawin 1990). In other cases, verbal but not visual memory deficits have been reported (Beatty et al. 1995). In particular, so far, we are not aware of any hint to a connection between cocaine and WM update (as measured by the N-back and Mental Counters tasks), so that recreational users would be expected to function normally in tasks tapping WM updating.

Demonstrating a dissociation between flexibility and updating would be of considerable theoretical relevance, especially with regard to the underlying neuromodulatory systems. Measures like eyeblink rates (as used by Colzato et al. 2008b) are assumed to indicate individual dopaminergic functioning (Blin et al. 1990; Karson 1983; Taylor et al. 1999), so that the observed correlation between eyeblink rates and recreational cocaine use points to the involvement of dopamine in cocaine-related cognitive deficits. However, this measure is too general to distinguish between the dopaminergic pathways and/or the receptor families involved. Interestingly, WM processes seem to be mainly driven by the (D1-dominated) mesocortical pathway (Sawaguchi and Goldman-Rakic 1991), whereas inhibition seems to be mainly driven by the (D2dominated) nigrostriatal pathway (Frank et al. 2004). A recent behavioral genetics study has linked cognitive flexibility to the DRD2 TAQ I A polymorphism (Reuter et al. 2006), which is associated with a selective impairment of the D2 receptor family. This impairment went along with increased flexibility, which fits with the idea that dopaminergic D2 receptors are involved in flexibility and inhibition (Franken et al. 2007). Along these lines, finding recreational use of cocaine to impact flexibility but not updating may point to an interesting commonality between flexibility and inhibition and the underlying neuromodulatory mechanism.

To test our hypothesis, in order to avoid long testing protocols that may be problematic in motivational and fatigue term, we carried out two separate studies with different subjects: study 1 testing cognitive flexibility and study 2 testing updating of WM. 


\section{Study 1 (flexibility)}

Materials and methods

\section{Participants}

Forty young healthy adults (33 men and 7 women) were compensated for their collaboration. They constituted the two groups of recreational cocaine polydrug users and cocaine-free controls. The sample was drawn from 100 adults in the Leiden and Delft metropolitan area, who volunteered to participate in studies of behavioral pharmacology. Participants were recruited via ads posted on community bulletin boards and by word of mouth. Following Colzato et al. (2007) and Colzato and Hommel (2008), we made sure that the users met the following criteria: (1) a monthly consumption (1-4 g) by snorting route for a minimum of 1 year, (2) no clinically significant medical disease, (3) no use of medication criteria, and (4) no family history of alcoholism and/or substance use disorder. No user met more than two of the seven criteria that according to the American Psychiatric Association DSM-IV and the World Health Organization (ICD-10) define addiction: tolerance, withdrawal, difficulty controlling the use, negative consequences for job, family and health, significant time or emotional energy spent in searching/consuming the drug, put off or neglected activities because of the use, and desire to cut down the use. Cocaine-free controls met the same criteria except that no one reported any history of past or current cocaine use. Participants were selected via a phone interview using the Mini International Neuropsychiatric Interview (M. I.N.I.; Lecrubier et al. 1997). The M.I.N.I. is a wellestablished brief diagnostic tool in clinical and stress research (Sheehan et al. 1998; Elzinga et al. 2007, 2008; Colzato et al. 2008a) that screens for several psychiatric disorders including schizophrenia, depression, mania, attention deficit/hyperactivity disorder (ADHD), and obsessivecompulsive disorder. Based on the interview, we excluded 20 of the 100 potential participants because of hints to a possible psychiatric disorder (ADHD, mania) and/or current medication.

Participants were asked to refrain from taking all psychoactive drugs for at least 2 weeks before the test, not to consume alcohol on the night before the experimental session, and to have a normal night rest. Participants' compliance with the instruction was encouraged by taking a (not further analyzed) saliva sample at the beginning of the session (cf., Colzato et al. 2004).

Participants in the two groups were matched for ethnicity (100\% Caucasian), age, sex, IQ (measured by Raven's Standard Progressive Matrices (SPM); Raven et al. 1988), and alcohol consumption. Although cocaine was the preferred drug of use for the participants, all 20 were polydrug users in also consuming alcohol on at least a weekly basis and using cannabis (19), MDMA (14), amphetamine (4), GHB (3), and psilocybin mushrooms (1). All cocaine users (and nonusers) reported to have never used LSD, barbiturates, steroids, solvents, or opiates. Demographic and drug use statistics are provided in Table 1.

Written informed consent was obtained from all participants after the nature of the study was explained to them. The protocol and the remuneration arrangements of 30 euro were approved by the institutional review board (Leiden University, Institute for Psychological Research).

\section{Computerized tasks}

The tasks used in this study have been previously employed to systematically investigate the neurotoxic effects of recreational MDMA use (Daumann et al. 2004; von Geusau et al. 2004). Similar to the studies and following Miyake et al. (2000), we defined cognitive flexibility as the ability to adapt and restructure cognitive representations in response to changing situational demands (cf., Monsell 1996). Two tasks were used to assess flexibility, the Wisconsin Card Sorting Test (WCST; Grant and Berg 1948) and the dots-triangles task (Huizinga et al. 2006).

All participants were tested individually. Individual IQs were determined by means of a 30-min reasoning-based intelligence test (SPM). The SPM assesses the individual's ability to create perceptual relations and to reason by analogy independent of language and formal schooling; it is a standard, widely used test to measure Spearman's general intelligence factor and of fluid intelligence in particular (Raven et al. 1988). Participants provided a saliva sample, completed the SPM, and subsequently performed the behavioral tasks measuring cognitive flexibility and WM capacity. Participants were allowed to take a short break (maximal $10 \mathrm{~min}$ ) between task blocks. The experiment was controlled by a PC attached to a 17 -in. monitor with a refresh rate of $120 \mathrm{~Hz}$. Participants were seated approximately $0.5 \mathrm{~m}$ from the screen.

Wisconsin Card Sorting Task The WCST is an elective measure of cognitive flexibility because it measures the ability to shift attention according to changes in the dimensional relevance of stimuli. This task requires the deduction of correct sorting rules and their flexible execution. Against a light gray background, four key cards were presented at the top of the screen and were numbered from 1 to 4 . The response cards were taken from the original version of the WCST (Grant and Berg 1948) and were presented one at a time at the bottom of the screen. The task required participants to match the series of response cards with any of four key cards by pressing the number corresponding to that key card. The display remained until a choice was given. 
Feedback followed the response and consisted of a "+" sign if the response was correct, or a "-" sign if the response was incorrect. Response cards could be matched on color (red, green, blue, yellow), shape (triangle, star, cross, circle), or number $(1,2,3,4)$. Once the participant made ten consecutive correct sorts, the sorting principle changed. The task was terminated either after the participant completed six categories (e.g., shape, color, form, color, form, shape), or after the maximum of 128 trials was reached. The order of the sorting principles was randomized, with the constraint that the same sorting principles did not occur consecutively. The test was administered according to the procedure outlined in the Heaton Manual (Heaton et al. 1993). The variables of interest were the number of categories achieved, the proportion of perseverative errors (i.e., the total number of errors that occur when a participant is required to switch to another sorting principle and then persists in responding to the previously correct sorting principle, relative to the number of trials administered, and multiplied by 100), and the proportion of conceptual level responses (i.e., the total number of consecutive correct responses that occur in runs of three or more relative to the number of trials administered, and multiplied by 100).

Dots-triangles task The task was modeled after Huizinga et al. (2006) and involves the maintenance and switching of response set. Varying numbers of either red dots or green triangles were presented in a $4 \times 4$ grid on the screen (i.e., three to eight dots or triangles per half of the grid; equally distributed). During the "dots" task, participants had to decide whether there are more dots in the left or the right part of the grid (block 1; 30 practice trials, 50 experimental trials). During the "triangles" task, participants had to decide whether there are more triangles in the top or in the bottom part of the grid (block 2; 30 practice trials, 50 experimental trials). Blocks 1 and 2 were administered in randomized order. In the third block (90 practice trials, 150 experimental trials), a series of four "dots" trials and a series of four "triangles" trials were alternately presented to the participants. A stimulus remained on the screen until a response was given. Participants had 3,500 ms to respond. The time interval between the response and the next stimulus was $900-1,100 \mathrm{~ms}$. The variables of interest were the median response latencies on repetition and alternation trials.

\section{Statistical analysis}

We adopted a significance level of $p<0.05$. Independent samples $t$ tests were used to analyze binary comparisons and analyses of variance (ANOVAs) otherwise. $t$ tests were performed for analysis of age, sex, IQ, and alcohol consumption and in the Wisconsin Card Sorting Test differences between recreational cocaine polydrug users and cocaine-free controls. Differences between groups in the other cognitive task measures were analyzed using repeated measures ANOVA with group (cocaine users vs cocaine-free controls) as between-subject factor. Spearman's correlation coefficients were computed between the degree of exposure to cocaine and to other drugs (especially MDMA, cannabis, and amphetamine) and cognitive performance in order to test whether the magnitude of cognitive impairments is proportional to the amount of cocaine consumed and to control for the consumption of those drugs that varied significantly between the cocaine group and controls. Effect magnitudes were assessed by calculating partial Eta squared $\left(\eta^{2} p\right)$ and Cohen's $d$ (Cohen 1988) for repeated measures ANOVAs.

Results

\section{Participants}

No significant group differences were obtained for age, $t(37)=1.10, p=0.28$; intelligence, $t(37)=-1.61, p=0.14$; or alcohol consumption, $t(37)=1.02, p=0.30$. Table 1 shows drug-use profiles for the two groups. The recreational cocaine polydrug group had consumed significantly higher quantities of MDMA, cannabis, GHB, and speed.

\section{Tasks}

The results per cognitive task are summarized below and in Table 2. Due to technical failure, the data of one participant (one cocaine-free control) from some of the tasks were incomplete.

Wisconsin Card Sorting Task As compared to cocaine-free controls, cocaine users made more perseverative errors, $t(37)=3.36, p=0.002$; completed fewer categories, $t(37)=$ $-2.35, p=0.025$; and showed less insight into conceptual level, $t(37)=-2.54, p=0.016$.

Dots-triangles task For the single-task blocks, Reaction Times (RTs) and errors did not vary significantly between the two groups, $F(1,37)=2.37, p>0.05, M S E=249077.71$, $\eta^{2} p=0.07$, and $F<1$, respectively. The mixed block RTs revealed a significant main effect of task repetition, $F(1,37)=131.92, p<0.0001, M S E=17395.44, \eta^{2} p=0.78$; and a task repetition $\times$ group interaction, $F(1,37)=5.37$, $p<0.05, M S E=17395.44, \eta^{2} p=0.13$. Recreational cocaine polydrug users showed more pronounced switching costs (i. e., a greater difference in RT between alternation trials and repetition trials) than the cocaine-free controls. In the error analysis, task repetition revealed a main effect, $F(1,37)=$ 
Table 1 Demographic characteristics and self-reported use of cocaine and other psychoactive drugs for study 1

Standard errors are presented within parentheses

Raven IQ IQ measured by means of the Raven's Standard Progressive Matrices, Monthly drinks monthly number of standard alcoholic drinks

${ }^{\text {a }}$ Nonsignificant difference

$* p<0.05$

$* * p<0.01$

\begin{tabular}{|c|c|c|}
\hline Sample & Controls & Recreational users \\
\hline$N(\mathrm{M}: \mathrm{F})^{\mathrm{a}}$ & $20(17: 3)$ & $20(16: 4)$ \\
\hline Age (years) ${ }^{a}$ & $23.0(2.2)$ & $23.9(4.6)$ \\
\hline Raven IQ ${ }^{\mathrm{a}}$ & $112.6(4.6)$ & $109.2(4.4)$ \\
\hline Monthly drinks ${ }^{\mathrm{a}}$ & $40.1(28.4)$ & $50.3(48.5)$ \\
\hline Lifetime exposure (MDMA) $)^{\mathrm{a}, * *}$ & $6.8(5.0)$ & $70(112)$ \\
\hline Monthly exposure (joints)* & $4.4(3.0)$ & $18.6(26.8)$ \\
\hline 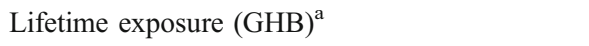 & 0 & $0.24(1.0)$ \\
\hline Lifetime exposure (grams speed)* & 0 & $3.6(10.8)$ \\
\hline Lifetime exposure (psilocybin) $^{\mathrm{a}}$ & 0 & $0.08(0.29)$ \\
\hline Highest regular frequency (times per month) & 0 & $5.8(3.6)$ \\
\hline Highest amount in a $12-\mathrm{h}$ period (peak; grams) & 0 & $1.8(1.5)$ \\
\hline Monthly exposure (grams cocaine) & 0 & $2.4(1.6)$ \\
\hline Lifetime exposure (grams cocaine) & 0 & $146(160)$ \\
\hline Duration of use in years & 0 & $5(3.8)$ \\
\hline Monthly money cocaine (euro) & 0 & $108(55)$ \\
\hline
\end{tabular}

28.78, $p<0.001, M S E=0.209, \eta^{2} p=0.44$, due to fewer errors when the task was repeated than alternated. Group was not involved in any significant effect, suggesting that the task repetition $\times$ group interaction in the RTs does not reflect a speed-accuracy trade-off.

\section{Correlations}

Lifetime cocaine exposure positively correlated with switching costs, $r(19)=0.456, p=0.05$, and with perseverative errors, $r(19)=0.507, p=0.022$, while peak and monthly cocaine dose and monthly drinks and cigarettes, even though it followed the same trend, did not. No significant correlations were obtained between exposure to other drugs and cognitive performance.

\section{Study 2 (WM)}

Materials and methods

\section{Participants}

Forty young healthy adults (33 men and 7 women) were compensated for their collaboration. They constituted the two groups of recreational cocaine polydrug users and cocaine-free controls.

As for study 1, although cocaine was the preferred drug of use for the participants, all 20 were polydrug users in also consuming alcohol on at least a weekly basis and using cannabis (19), MDMA (14), amphetamine (6), and GHB (2). All cocaine users (and nonusers) reported to have never used LSD, barbiturates, steroids, solvents, or opiates. Demographic and drug use statistics are provided in Table 3.

The same standard matching criteria from study 1 were applied, see Table 3, and the remaining method was the same.

\section{Computerized tasks}

Research on WM has emphasized the existence of two different types of WM components, a rather passive storage component and an operational, executive component (Baddeley 1996). We employed the digit span task (Wechsler 1987) to assess the storage component and the mental counters task (Huizinga et al. 2006) and the N-back task (see, Kane et al. 2007, for a recent review) to assess the operational component.

As for study 1, all participants were tested individually, and the remaining method was the same as for study 1 .

Digit span task The digit span is a subtest of the Wechsler Adult Intelligence Scale-Revised (Wechsler 1987). Five series of numbers of increasing length (from 4 to 8 in the forward condition and 3 to 7 in the backward condition) were read to each participant at the rate of one digit per second. Participants had to repeat the numbers in the same order (forward condition) or in reversed order (backward condition). Each set length was tested twice. For each correctly repeated digit set, the number of digits was added up, and the scores for the forward and backward conditions were combined, so that scores could range from 0 to 12 .

Mental counters task The mental counters task required participants to retain numerical information active in their WM. Participants had to keep track of the values of two or 
Table 2 Means response latencies (RT) (in millisecond), error rates (PE) (in percent), and standard deviations of all relevant measures on cognitive flexibility tasks (study 1)

${ }^{*} p<0.05$ (significant group difference)

\begin{tabular}{|c|c|c|c|c|}
\hline Task & \multicolumn{2}{|c|}{ Recreational users } & \multicolumn{2}{|l|}{ Controls } \\
\hline \multicolumn{5}{|l|}{ Cognitive flexibility } \\
\hline \multirow[t]{2}{*}{ Dots-triangle } & RT & $\mathrm{PE}$ & RT & $\mathrm{PE}$ \\
\hline & $479(78)$ & $9.7(0.2)$ & $435(85)$ & $9.7(0.3)$ \\
\hline Switch costs & $298 *$ & 0.4 & $194 *$ & 0.3 \\
\hline \multicolumn{5}{|l|}{ WCST } \\
\hline Categories (\#) & & $4.2 *(0.4)$ & & $5.4 *(0.4)$ \\
\hline Perseverative errors $(\%)$ & & $15.5^{*}(1.9)$ & & $6.6^{*}(1.9)$ \\
\hline Conceptual level (\%) & & $55.4 *(4.4)$ & & $71.2 *(4.5)$ \\
\hline
\end{tabular}

three (blocked) independent "counters", which change rapidly and in random order. The counters consisted of a horizontal line, above or below which squares appear. Participants were required to add one to the value of the counter, when a square appeared above the line, and to subtract one, when it appeared below the line. When any counter reached a given criterion value, participants had to press a button. The series of stimuli presented comprised five or seven (chosen randomly and equiprobably); there were two blocks consisting of 15 response probes. Participants had 3,500 ms to respond. The interval between consecutive presentations of squares varied randomly between 1,000 and 1,300 ms (drawn from a uniform distribution). The main dependent variable was the proportion of correct trials.

N-back task Participants performed two N-back tasks consisting of the sequential visual presentation (stimulus onset asynchrony 2,000 $\mathrm{ms}$; duration of presentation 1,000 ms) of single letters (B, C, D, G, P, T, F, N, L). Participants had to press a button when a target stimulus appeared. Target definition differed with respect to the experimental condition. In the 1-back condition, targets were defined as stimuli within the sequence that were identical to the immediately preceding one. In the 2-back condition, participants had to respond if the presented letter matched the one that was presented two trials before. The 1-back and 2-back tasks differ in their amount of memory load and demands on executive control for the processing of information within working memory. Each block consisted of four cycles of the same task.

\section{Statistical analysis}

As for study 1, we adopted a significance level of $p<0.05$. Independent samples $t$ tests were used to analyze binary comparisons and ANOVAs otherwise.

$t$ tests were performed for analysis of age, sex, IQ, alcohol consumption, and digit span task. Differences between groups in the other cognitive tasks (for mental counters and N-back tasks) measures were analyzed using repeated
Table 3 Demographic characteristics and self-reported use of cocaine and other psychoactive drugs for study 2

Standard errors are presented within parentheses

Raven IQ IQ measured by means of the Raven's Standard Progressive Matrices, Monthly drinks monthly number of standard alcoholic drinks

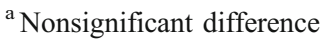

${ }^{*} p<0.05$

$* * p<0.01$

\begin{tabular}{|c|c|c|}
\hline Sample & Controls & Recreational users \\
\hline$N(\mathrm{M}: \mathrm{F})^{\mathrm{a}}$ & $20(16: 4)$ & $20(17: 3)$ \\
\hline Age (years) ${ }^{\mathrm{a}}$ & $22.9(2.0)$ & $24.0(4.3)$ \\
\hline Raven $\mathrm{IQ}^{\mathrm{a}}$ & $111.8(4.4)$ & $110.6(3.8)$ \\
\hline Monthly drinks ${ }^{\mathrm{a}}$ & $42.2(32.6)$ & $51.3(42.6)$ \\
\hline Lifetime exposure (MDMA)** & $6.8(5.0)$ & $68(114)$ \\
\hline Monthly exposure (joints)* & $4.8(3.8)$ & $16.2(24.0)$ \\
\hline Lifetime exposure $(\mathrm{GHB})^{\mathrm{a}}$ & 0 & $0.26(0.8)$ \\
\hline Lifetime exposure (grams speed)* & 0 & $4.0(12.3)$ \\
\hline Lifetime exposure psilocybin $^{a}$ & 0 & 0 \\
\hline Highest regular frequency (times per month) & 0 & $6.0(4.4)$ \\
\hline Highest amount in a $12-\mathrm{h}$ period (peak; grams) & 0 & $2.0(1.5)$ \\
\hline Monthly exposure (grams cocaine) & 0 & $2.8(2.0)$ \\
\hline Lifetime exposure (grams cocaine) & 0 & $140(170)$ \\
\hline Duration of use in years & 0 & $5(3.2)$ \\
\hline Monthly money cocaine (euro) & 0 & $103(48)$ \\
\hline
\end{tabular}


measures ANOVA with group (cocaine users vs cocaine-free controls) as between-subject factor. Spearman's correlation coefficients were computed between the degree of exposure to cocaine and to other drugs (especially MDMA, cannabis, and amphetamine) and cognitive performance in order to test whether the magnitude of cognitive impairments is proportional to the amount of cocaine consumed and to control for the consumption of those drugs that varied significantly between the cocaine group and controls. Effect magnitudes were assessed by calculating partial Eta squared $(\eta 2 p)$ and Cohen's $d$ (Cohen 1988) for repeated measures ANOVAs.

\section{Results}

\section{Participants}

No significant group differences were obtained for age, $t(38)=1.18, p=0.22$; intelligence, $t(38)=-1.70, p=0.10$; or alcohol consumption, $t(38)=0.96, p=0.34$. Table 3 shows drug-use profiles for the two groups. The recreational cocaine polydrug group had consumed significantly higher quantities of MDMA, cannabis, GHB, and speed.

\section{Tasks}

The results per cognitive task are summarized below and in Table 4. Due to technical failure, the data of one participant (one recreational cocaine polydrug user) from some of the tasks were incomplete.

Digit span task No significant group differences were obtained for the scores in the forward, $t(38)=0.84, p=0.41$, and backward condition, $t(38)=-1.00, p=0.32$.

Mental counters task RTs and accuracy were submitted to separate repeated measures ANOVA with WM load (low

Table 4 Means response latencies (in millisecond), error rates (in percent), and standard deviations of all relevant measures on working memory tasks (study 2)

\begin{tabular}{lllll}
\hline Task & \multicolumn{2}{l}{ Recreational users } & \multicolumn{2}{l}{ Controls } \\
\hline Working memory & & & & \\
Mental counters & RT & PE & RT & PE \\
& $457(32)$ & $8.7(0.2)$ & $420(32)$ & $9.2(0.2)$ \\
Digit span & & Accuracy & & Accuracy \\
Forward & & $8.5(2.2)$ & & $8.0(1.9)$ \\
Backward & & $7.2(1.5)$ & & $7.7(1.3)$ \\
N-back & RT & Accuracy & RT & Accuracy \\
1-back & $476(61)$ & $90.3(10.6)$ & $485(53)$ & $90.1(10.2)$ \\
2-back & $507(72)$ & $81.7(14.3)$ & $520(67)$ & $80.9(11.1)$ \\
\hline
\end{tabular}

$* p<0.05$ (significant group difference) versus high) and series length (short versus long), as within-subjects factors, and group (recreational cocaine polydrug users versus cocaine-free controls), as betweensubjects factor. Both RTs and accuracy were affected by series length, with longer series leading to longer RT, $F(1,38)=6.08, p<0.05, M S E=9400.01, \eta^{2} p=0.14$, and lower accuracy, $F(1,38)=6.13, p<0.05, M S E=0.969$, $\eta^{2} p=0.14$. Group was not involved in any significant effect, $F<1$.

$N$-back task RTs and accuracy were submitted to repeated measures ANOVA with WM load (1 versus 2) as withinsubjects factors and group (recreational cocaine polydrug users versus cocaine-free controls) as between-subjects factor. Both RTs and accuracy were affected by load, with load 2 leading to longer RT, $F(1,38)=10.26, p<0.05, M S E=$ 2367.62, $\eta^{2} p=0.22$, and lower accuracy, $F(1,38)=23.58$, $p<0.001, M S E=68.233, \eta^{2} p=0.39$. Group was not involved in any significant effect, $F(1,38)=0.17, p<0.68, M S E=$ 2367.62, $\eta^{2} p=0.005, d=0.002$; and $F(1,38)=0.08, p<$ $0.78, M S E=68.233, \eta^{2} p=0.002, d=0.001$; for RT and accuracy, respectively.

\section{Correlations}

No significant correlations were obtained between exposure to cocaine and to other drugs and cognitive performance.

\section{Discussion}

This study tested, for the first time, whether the recreational polydrug use of cocaine is associated with a detectable selective impairment in cognitive flexibility and/or WM. As expected, recreational users showed increased switching costs, reduced insight into the sorting strategies, more perseverative errors, and a reduced conceptual level of responses, all suggesting that recreational use is associated with impaired cognitive flexibility. At the same time, performance in recreational users did not differ from performance in nonusers with respect to WM functioning, which was true for both WM maintenance (i.e., the storage component) and WM updating (the executive component). Together with our previous observation of impaired inhibitory control in recreational users (Colzato and Hommel 2009; Colzato et al. 2007), these results fit with the available studies on chronic cocaine users, which reported impairments on tasks measuring mental flexibility and inhibition (Verdejo-Garcia et al. 2006; Verdejo-Garcia and Perez-Garcia 2007).

It is important to note that the causal relation between our results and the recreational use of cocaine is not straightfor- 
ward. Indeed, there are some hints to preexisting neurodevelopmental factors that may play a mediating role. For instance, monkeys that have preexisting lowered D2 receptor densities run a higher risks to use cocaine and to become addicted (Nader et al. 2006), and chronic human users may suffer preexisting problems in inhibitory control (Bechara 2005) and impulsivity (Verdejo-Garcia et al. 2008).

Even if data on the density of DAD1 and DAD2 receptors in recreational cocaine polydrug users are not yet available, one may speculate that recreational users suffer from reduced functioning of DAD2 receptors. If so, the apparent connection between D2 downregulation and flexibility and inhibition on the one hand and between D1 and WM on the other would account for our observation that recreational cocaine polydrug users suffer from impairments in flexibility but not in WM processes. Another not necessarily exclusive possibility is that the impairments on tasks measuring mental flexibility were the result of "silent strokes", small ischemic strokes accompanied by destruction of neuronal tissue occasionally associated with cocaine use (Westover et al. 2007). Moreover, given that our subjects reported the rather frequent joint consumption of cocaine and alcohol, it cannot be exclude that our pattern of results is due to the impact of cocaethylene, a psychoactive ethyl homolog of cocaine formed during the coadministration of cocaine and alcohol (Farrè et al. 1993).

As our participants were screened for several psychiatric disorders, we can rule out an account in terms of preexisting psychiatric disorders (as schizophrenia, ADHD, and obsessive-compulsive disorder) that have been associated with dopaminergic abnormalities (Davis et al. 1991; Pooley et al. 2007; Tripp and Wickens 2007). Particularly important was the matching of the age range and intelligence: cognitive flexibility and WM are known to be related to general intelligence (Ackerman et al. 2005; Colzato et al. 2006) and to decline with increasing age (Kray et al. 2002; Hartman and Warren 2005).

Given that no significant correlations were obtained between exposure to other drugs and cognitive performance, we tentatively attribute our findings mainly to cocaine consumption and only secondarily to use of these other drugs.

Indeed, even though the group difference in MDMA lifetime exposure was considerable, MDMA is known to affect WM and short-term memory (Bolla et al. 1998; Verkes et al. 2001) but not flexibility (Verdejo-Garcia et al. 2005, but see von Geusau et al. 2004). Therefore, if the use of MDMA would have confounded our results, we should have obtained a group effect on WM performance, which we did not.

Given the seemingly small amount of cocaine involved the present study, together with previous results showing that the recreational use of cocaine is associated with impairments in inhibitory control (Colzato et al. 2007; Colzato and Hommel 2009), it seems of societal relevance to devote more research on the functional significance of these deficits for the adaptive control of behavior. Indeed, the ability to adapt and restructure the cognitive system in response to changing situational demands is the basis for almost all "functional" everyday behavior, and it is needed in many real-life situations. The present findings also raise the question whether recreational cocaine polydrug users show impairments in other control functions, such as probabilistic learning, conflict control, and decision making related to the intact functioning of the ACC and OFC, two areas targeted by cocaine use (Bolla, et al. 1998; Bolla et al. 2004; Hester and Garavan 2004). Of particular, interest would be to look into decision making, considered by Verdejo-Garcia and Perez-Garcia (2007) to represent a fourth executive function, besides flexibility, inhibition, and updating, already championed by Miyake and colleagues (2000). It also remains to be demonstrated, among other things, that recreational use of cocaine is associated with changes in neuromodulation (e.g., reduced functioning of DAD2 receptors), cortical functioning (e.g., dysfunction in ventro-LPFC, $\mathrm{ACC}$, and $\mathrm{OFC}$ ), genetic vulnerability, and changes in expression of genes. For instance, it would be informative to investigate whether, among recreational cocaine polydrug users, there is also a genetic association with the Taq A1 of the DRD2 polymorphism as in the case of alcohol dependence (Blum et al. 1990) and cocaine addiction (Noble et al. 1993). This association would be useful as marker for a genetic vulnerability, even in the case of recreational substance use (see for a review, Verdejo-Garcia et al. 2008). It would be also interesting to look whether the recreational use of cocaine increases gene expression and promotes release of the $\mathrm{k}$ opioid ligand dynorphin in the striatum, as in the case of cocaine addiction (Kreek et al. 2005).

Acknowledgments We thank Marieke van der Meer, Linda van Hooidonk, Martine van Nierop, Doris van Dijk, Brenda de Lang, Katie Achterberg, Jasper S. van der Spek, Caspar van der Draai, Robin Frielink, Kim Eva Walma, and Ivor Vink for their enthusiasm and invaluable assistance in recruiting, testing the participants of this study, and collecting the data.

Funding The research of LSC is supported by NWO (Netherlands Organization for Scientific Research).

Competing interests The authors have declared that no competing interests exist.

Open Access This article is distributed under the terms of the Creative Commons Attribution Noncommercial License which permits any noncommercial use, distribution, and reproduction in any medium, provided the original author(s) and source are credited. 


\section{References}

Ackerman PL, Beier ME, Boyle MO (2005) Working memory and intelligence: the same or different constructs? Psychol Bull 131:30-60

Baddeley A (1996) Exploring the central executive. Q J Exp Psychol 49: A, 5-28

Beatty WW, Katzung VM, Moreland VJ, Nixon SJ (1995) Neuropsychological performance of recently abstinent alcoholics and cocaine users. Drug Alcohol Depend 37:247-253

Bechara A (2005) Decision making, impulse control and neurocognitive perspective. Nat Neurosci 8:1458-1463

Blin O, Masson G, Azulay JP, Fondarai J, Serratrice G (1990) Apomorphine-induced blinking and yawning in healthy volunteers. Br J Clin Pharmacol 30:769-773

Blum K, Noble EP, Sheridan PJ, Montgomery A, Ritchie T, Jagadeeswaran P, Nogami H, Briggs AH, Cohn JB (1990) Allelic association of human dopamine D2 receptor gene in alcoholism. JAMA 263:2055-2060

Bolla KI, Cadet J, London ED (1998) The neuropsychiatry of chronic cocaine abuse. J Neuropsych Clin N 10:280-289

Bolla KI, Ernst M, Kiehl KA, Mouratidis M, Eldreth DA et al (2004) Prefrontal cortical dysfunction in abstinent cocaine abusers. J Neuropsych Clin N 16:456-464

Cohen J (1988) Statistical power analysis for the behavioral sciences, 2nd edn. Lawrence Erlbaum Associates, Hillsdale

Colzato LS, Hommel B (2008) Cannabis, cocaine, and visuomotor integration: evidence for a role of dopamine D1 receptors in binding perception and action. Neuropsychologia 46:1570-1575

Colzato LS, Hommel B (2009) Recreational use of cocaine eliminates inhibition of return. Neuropsychology 23:125-129

Colzato LS, Erasmus V, Hommel B (2004) Moderate alcohol consumption in humans impairs feature binding in visual perception but not across perception and action. Neurosci Lett 360:103-105

Colzato LS, van Wouwe NC, Lavender T, Hommel B (2006) Intelligence and cognitive flexibility: fluid intelligence correlates with feature "unbinding" across perception and action. Psychon Bull Rev 13(6):1043-1048

Colzato LS, van den Wildenberg WPM, Hommel B (2007) Impaired inhibitory control in recreational cocaine users. PLoS ONE 2(11): e1143. doi:10.1371/journal.pone. 0001143

Colzato LS, Kool W, Hommel B (2008a) Stress modulation of visuomotor binding. Neuropsychologia 46:1542-1548

Colzato LS, van den Wildenberg WPM, Hommel B (2008b) Reduced spontaneous eye blink rates in recreational cocaine users: evidence for dopaminergic hypoactivity. PLoS ONE, http://dx. plos.org/10.1371/journal.pone.0003461

Cools R (2006) Dopaminergic modulation of cognitive functionimplication for L-dopa therapy in Parkinson's disease. Neurosci Biobehav Rev 30:1-34

Davis K, Kahn R, Ko G, Davidson M (1991) Dopamine in schizophrenia: a review and reconceptualization. Am J Psych 148:1474-1486

Daumann J, Fischermann T, Heekeren K, Thron A, Gouzoulis-Mayfrank E (2004) Neural mechanisms of working memory in ecstasy (MDMA) users who continue or discontinue ecstasy and amphetamine use: evidence from an 18-month longitudinal functional magnetic resonance imaging study. Biol Psychiatry 56:349-355

Elzinga BM, Ardon AM, Heijnis MK, de Ruiter MB, van Dyck R, Veltman DJ (2007) Neural correlates of enhanced workingmemory performance in dissociative disorder: a functional MRI study. Psychol Med 37:235-245

Elzinga BM, Roelofs K, Tollenaar MS, Bakvis P, van Pelt J, Spinhoven P (2008) Diminished cortisol responses to psychosocial stress associated with lifetime adverse events: a study among healthy young subjects. Psychoneuroendocrinology 33:227-237
European monitoring centre for drugs and drug addiction (2007). The state of the drugs problem in Europe, Annual Report 2007. Available: http://www.emcdda.europa.eu/publications/annual-report/2007

Farrè M, de la Torre R, Llorente M, Lamas X, Ugena B, Segura J, Camí J (1993) Alcohol and cocaine interactions in humans. J Pharmacol Exp Ther 266:1364-1373

Fillmore MT, Rush CR (2002) Impaired inhibitory control of behaviour in chronic cocaine users. Drug Alcohol Depend 66:265-273

Frank MJ, Seeberger L, O'Reilly RC (2004) By carrot or by stick: cognitive reinforcement learning in Parkinsonism. Science 306:1940-1943

Franken IHA, van Strien JW, Franzek EJ, van de Wetering BJ (2007) Error-processing deficits in patients with cocaine dependence. Biol Psychol 75:45-51

Friedman NP, Miyake A (2004) The relations among inhibition and interference control functions: a latent-variable analysis. J Exp Psychol Gen 133:101-135

Friedman NP, Miyake A, Corley RP, Young SE, DeFries JC, Hewitt JK (2006) Not all executive functions are related to intelligence. Psychol Sci 17:172-179

Grant DA, Berg EA (1948) A behavioural analysis of degree of reinforcement and ease of shifting to new responses in a Weigltype card sorting problem. J Exp Psychol 38:404-411

Hartman M, Warren LH (2005) Explaining age differences in temporal memory. Psychol Aging 20(4):654-656

Heaton RK, Chelune GJ, Talley JL, Kay GG, Curtiss G (1993) Wisconsin card sorting test manual: revised and expanded. Psychological Assessment Resources, Inc., Odessa, Fla.

Hester R, Garavan H (2004) Executive dysfunction in cocaine addiction: evidence for discordant frontal, cingulate, and cerebellar activity. J Neurosci 24:11017-11022

Hoff AL, Riordan H, Morris L, Cestaro V, Wieneke M, Alpert R, Wang G-J, Volkow N (1996) Effects of crack cocaine on neurocognitive function. Psychiatr Res 60:167-176

Huizinga M, Dolan CV, Van der Molen MW (2006) Age-related change in executive function: developmental trends and a latent variables analysis. Neuropsychologia 44:2017-2036

Jovanovski D, Erb S, Zakzanis KK (2005) Neurocognitive deficits in cocaine users: a quantitative review of the evidence. J Clin Exp Neuropsychol 27:189-204

Kane MJ, Conway ARA, Miura TK, Colflesh GJH (2007) Working memory, attention control, and the N-back task: a question of construct validity. JEP:LMC 33:615-622

Karson CN (1983) Spontaneous eye-blink rates and dopaminergic systems. Brain 106:643-653

Kray J, Li KZH, Lindenberger U (2002) Age-related changes in taskswitching components: the role of task uncertainty. Brain Cogn 49:363-381

Kreek MJ, Bart G, Lilly C, LaForge KS, Nielsen DA (2005) Pharmacogenetics and human molecular genetics of opiate and cocaine addictions and their treatments. Pharmacol Rev 57:1-26

Kübler A, Murphy K, Garavan H (2005) Cocaine dependence and attention switching within and between verbal and visuospatial working memory. Eur J NeuroSci 21:1984-1992

Lecrubier Y, Sheehan DV, Weiller E, Amorim P, Bonara I et al (1997) The Mini International Neuropsychiatric Interview (MINI). A short diagnostic structured interview: reliability and validity according to the CIDI. Eur Psychiatr 12:224-231

Miller EK (2000) The prefrontal cortex and cognitive control. Nat Rev Neurosci 1:59-65

Miyake A, Friedman NP, Emerson MJ, Witzki AH, Howerter A, Wager T (2000) The unity and diversity of executive functions and their contributions to complex "frontal lobe" tasks: a latent variable analysis. Cogn Psychol 41:49-100

Monsell S (1996) Control of mental processes. In: Bruce V (ed) Unsolved mysteries of the mind. Erlbaum, Hove, pp 93-148 
Monterosso J, Ehrman R, Napier KL, O’Brien CP, Childress AR (2001) Three decision-making tasks in cocaine-dependent patients: do they measure the same construct? Addiction 96: 1825-1837

Nader MA, Morgan D, Gage HD, Nader SH, Calhoun TL et al (2006) PET imaging of dopamine D2 receptors during chronic cocaine self-administration in monkeys. Nat Neurosci 9:1050-1056

Noble EP, Blum K, Khalsa ME, Ritchie T, Montgomery A, Wood RC, Fitch RJ, Ozkaragoz T, Sheridan PJ, Anglin MD et al (1993) Allelic association of the D2 dopamine receptor gene with cocaine dependence. Drug Alcohol Depend 33:271-285

O'Malley SS, Gawin FH (1990) Abstinence symptomatology and neuropsychological impairment in chronic cocaine abusers. NIDA Res Monogr 101:179-190

Pooley EC, Fineberg N, Harrison PJ (2007) The met158 allele of catechol-O-methyltransferase (COMT) is associated with obsessive-compulsive disorder in men: case-control study and metaanalysis. Mol Psychiatry 12:556-561

Raven JC, Court JH, Raven J (1988) Manual for Raven's progressive matrices and vocabulary scales. Lewis, London

Reuter M, Roth S, Holve K, Hennig J (2006) Identification of first candidate genes for creativity: a pilot study. Brain Res 1069:190-197

Sawaguchi T, Goldman-Rakic PS (1991) D1 dopamine receptors in prefrontal cortex: involvement in working memory. Science 251:947-950

Sheehan DV, Lecrubier Y, Sheenan KH, Amorim P, Janavs J, Weiller E, Hergueta T, Baker R, Dunbar GC (1998) The MiniInternational Neuropsychiatric Interview (M.I.N.I.): the development and validation of a structured diagnostic psychiatric interview for DSM-IV and ICD-10. J Clin Psychiatr 59:22-23

Taylor JR, Elsworth JD, Lawrence MS, Sladek JR, Roth RH et al (1999) Spontaneous blink rates correlate with dopamine levels in the caudate nucleus of MPTP-treated monkeys. Exp Neurol 158:214-220

Tripp G, Wickens JR (2007) Dopamine transfer deficit: a neurobiological theory of altered reinforcement mechanisms in ADHD. J Child Psychol and Psychiatry . doi:10.1111/j.1469-7610.2007.01851
Verdejo-Garcia AJ, Lopez-Torrecillas F, Aguilar de Arcos F, PerezGarcia M (2005) Differential effects of MDMA, cocaine, and cannabis use severity on distinctive components of the executive functions in polysubstance users: a multiple regression analysis. Addict Behav 30:89-101

Verdejo-Garcia A, Bechara A, Recknor E (2006) Executive dysfunction in substance-dependent individuals during drug use and abstinence: an examination of the behavioural, cognitive, and emotional correlates of addiction. J Int Neuropsychol Soc 12:405-415

Verdejo-Garcia AJ, Perez-Garcia M (2007) Profile of executive deficits in cocaine and heroin polysubstance users: common and differential effects on separate executive components. Psychopharmacology 190:517-530

Verdejo-Garcia AJ, Lawrence AJ, Clarke L (2008) Impulsivity as a vulnerability marker for substance-use disorders: review of findings from high-risk research, problem gamblers and genetic association studies. Neurosci Biobehav Rev 32:777810

Verkes RJ, Gijsman HJ, Pieters MSM, Schoemaker RC, de Visser S, Kuijpers M, Pennings EJM, de Bruin D, Van de Wijngaart G, Van Gerven JMA, Cohen AF (2001) Cognitive performance and serotonergic function in users of ecstasy. Psychopharmacology 153:196-202

Volkow ND, Fowler JS, Wang GJ (1999) Imaging studies on the role of dopamine in cocaine reinforcement and addiction in humans. J Psychopharmacol 13:337-345

von Geusau NA, Stalenhoef P, Huizinga M, Snel J, Ridderinkhof KR (2004) Impaired executive function in male MDMA ("ecstasy") users. Psychopharmacology 175:331-341

Wechsler D (1987) Manual for the Wechsler Memory Scale-Revised. The Psychological Corporation, San Antonio

Westover AN, McBride S, Haley RW (2007) Stroke in young adults who abuse amphetamines or cocaine: a population-based study of hospitalized patients. Arch Gen Psychiatry 64:495-502 